\title{
ORALIDADE E ESCRITA: UMA REVISÃO
}

\author{
ANA MARIA DE OLIVEIRA GALVÃO \\ Faculdade de Educação da Universidade Federal de Minas Gerais \\ anamgalvao@uol.com.br

\section{ANTÔNIO AUGUSTO GOMES BATISTA} \\ Faculdade de Educação da Universidade Federal de Minas Gerais \\ aagbatista@aol.com
}

\begin{abstract}
RESUMO
O artigo faz uma revisão crítica dos estudos que se dedicam à análise das relações entre oralidade e escrita e às supostas conseqüências da introdução ou difusão da escrita e da imprensa em sociedades e em grupos sociais. Para isso, os autores caracterizam a emergência do campo de estudos sobre o tema, suas principais abordagens e seu estágio atual. COMUNICAÇÃO VERBAL - ESCRITA - RELAÇÕES SOCIAIS
\end{abstract}

\section{ABSTRACT}

ORALITY AND LITERACY: A REVIEW. This article is a critical review of studies which dedicated themselves to analyze the relationship between orality and writing and the alleged consequences of the access or dissemination of both writing and press in societies and social groups. Bearing this in mind, the authors describe the emergence of a field of studies on the subject, its main approaches and current stage.

VERBAL COMMUNICATION - WRITING - SOCIAL RELATIONS 
No Brasil, nas últimas décadas, tem crescido o número de trabalhos que investigam aspectos da história da escrita no país. Realizados em campos disciplinares diferentes, esses trabalhos pesquisam, por exemplo, os modos pelos quais indivíduos, famílias e grupos sociais, em diferentes períodos e espaços sociais, se inserem na cultura escrita. Diante dessa constatação, neste artigo buscamos, a partir de diferentes autores, condensar as principais idéias de estudos feitos principalmente a partir da década de 60, em vários países, e trazer reflexões que possam subsidiar pesquisadores interessados na temática. Esses estudos, ao se debruçarem sobre as relações entre culturas orais e letradas, sobre as conseqüências da introdução da escrita e da imprensa nas sociedades tradicionais, sobre a constituição de modos diferentes de pensamento em culturas diversas, revelam-se um instrumento fundamental na percepção e compreensão de aspectos relacionados à história da cultura escrita no país.

\section{A EMERGÊNCIA DO CAMPO DE ESTUDOS}

Os estudos que buscam investigar culturas orais e escritas emergiram, sistematicamente, no início dos anos 1960. Havelock (1995) localiza, entre 1962 e 1963, quatro publicações fundamentais que contribuíram para a constituição desse novo campo de pesquisas. Esses trabalhos, versando sobre temas diferentes e originários de países diversos, tinham em comum o fato de colocarem a oralidade em destaque: em 1962, foram publicados The Gutenberg Galaxy', de McLuhan, no Canadá, e La pensée sauvage², de LéviStrauss, na França; em 1963, Jack Goody e lan Watt publicaram o artigo "The consequences of literacy"3 na Inglaterra, e Eric Havelock publicou Preface to Plato ${ }^{4}$ nos Estados Unidos. Naquele momento, as próprias transformações por que passavam os meios de comunicação contribuíram para que a oralidade e a escrita fossem reconsideradas objeto de estudo de destaque, segundo Havelock (1995).

I. A galáxia de Gutenberg(McLuhan, 1972)

2. O pensamento selvagem (Lévi-Strauss, 1983).

3. "As conseqüências do alfabetismo" (Goody, Watt, 1963, não traduzido para o português).

4. Prefácio a Platão (Havelock, 1997). 
Na mesma direção, Ong (1998) situa nas décadas de 1960 e 1970 esse movimento acadêmico de análise das relações entre culturas orais e escritas. Os trabalhos realizados nesse período, em diversas áreas de conhecimento, como a Antropologia, a Sociologia e a Psicologia, enfatizaram o caráter oral da linguagem e as profundas implicações, em todos os níveis, da introdução da escrita em culturas tradicionais. Muitas dessas pesquisas debruçaram-se, por meio de trabalhos de campo, sobre sociedades ainda orais, buscando vestígios daquilo que se convencionou denominar oralidade primária: "melodias, cantos, epopéias, danças, exibições e músicas, ainda preservados oralmente e transmitidos de geração a geração entre as sociedades tribais..." (Havelock, 1995). De maneira semelhante, Cook-Gumperz e Gumperz ( 198 I) situam as origens das pesquisas sobre os efeitos culturais do letramento nos estudos de folcloristas e pesquisadores da área de literatura que investigaram os processos pelos quais os grandes épicos eram transmitidos nas sociedades não letradas, como é o caso dos trabalhos de Lord (1960) e Havelock (1963).

Na avaliação de Ong (1998), pode-se considerar a emergência desses estudos com preocupações semelhantes em um mesmo período histórico como um movimento de redescoberta da oralidade, decorrente do estabelecimento, por Saussure, do primado oral da linguagem. Do mesmo modo, trabalhos de antropólogos estruturalistas realizados anteriormente haviam analisado a tradição oral em sociedades sem escrita. Para Ong ( 1998), a "novidade" dos estudos mais recentes estava na preocupação dos pesquisadores em contrastar, realizando oposições, a oralidade e a escrita, em diversos níveis. Nesse sentido, diversos autores (por exemplo, Ong, 1998 e Havelock, 1995) citam o trabalho de Milmam Parry, na área de estudos literários, ainda nos anos 1920 na lugoslávia, como um dos marcos iniciais desse novo campo de estudos. Na tese L'épithète traditionelle dans Homère ${ }^{5}$, publicada em Paris em 1928, Parry analisou a Ilíada e a Odisséia, trabalho que teve prosseguimento na obra de seu discípulo Albert Lord que, em 1960, publicou The single of the tales ${ }^{6}$. Naquele momento, Lord divulgou o material que Parry havia recolhido entre bardos, com uma análise dos cantores tradicionais iugoslavos. Havelock

5. O epíteto tradicional em Homero (Parry, 1928, não traduzido para o português).

6. O cantor de histórias (Lord, 1960, não traduzido para o português). 
cita ainda diversos outros trabalhos que antecederam a década de 60 e que, de algum modo, haviam se dedicado ao contraste entre oralidade e escrita como, Ramus: method and decay of dialogue ${ }^{7}$, de Walter Ong, publicado em 1958. Estudos dessa ordem provocaram também um novo interesse pela palavra escrita e seu principal suporte contemporâneo: o texto impresso e, em particular, o livro. Nessa direção, destacam-se algumas obras que centraram suas análises nas conseqüências da palavra escrita e impressa em sociedades e épocas determinadas, como é o caso de L'apparition du livre ${ }^{8}$, de Henri-Jean Martin e Lucien Febvre, publicado em 1958, e The printing press as an agent of change: communication and cultural transformation in early modern Europe? de Elizabeth Eisenstein, publicado em 1979. Os efeitos da introdução da escrita e da imprensa em sociedades não letradas têm sido, pois, uma das principais questões que norteiam esse novo campo de estudos.

Segundo Havelock, o desenvolvimento crescente, a partir dos anos 60, de pesquisas no campo de estudos que investiga as relações entre o oral e o escrito, coloca, na atualidade (o texto foi escrito em 1987), os conceitos de oralidade e de oralismo em uma situação diferente da que ocupavam anteriormente, ganhando maior importância acadêmica. Esses conceitos contribuem para a caracterização de sociedades que, dispensando o uso da escrita, têmse valido da linguagem oral em seus processos de comunicação. As expressões têm sido utilizadas também para identificar um certo tipo de consciência, supostamente criada pela oralidade (Havelock, 1995). Essas preocupações têm sido centrais nos estudos realizados nesse campo.

\section{Os diversos tipos de culturas}

Alguns autores, em estudos realizados sobre as relações entre oralidade e escrita, têm, pois, tipificado as diferentes culturas, a partir do papel que nelas ocupam as palavras oral e escrita. Ginzburg (1987), por exemplo, ao estudar as leituras do moleiro Menocchio, buscou investigar se o fato de os leito-

7. Ramus: método e decadência do diálogo (Ong, 1998, não traduzido para o português).

8. O aparecimento do livro (Martin, Febvre, 1992).

9. A revolução da cultura impressa: os primórdios da Europa moderna (Eisenstein, 1998). 
res estarem mergulhados em uma cultura predominantemente oral não interferia na recepção do texto, modificando-o, remodelando-o, chegando mesmo a alterar sua natureza. Em que medida, então, a oralidade modelava certos padrões de leitura, que interferiam na relação com o texto escrito? Mas o que seria um "contexto marcado pela oralidade"? As culturas pouco letradas possuiriam características tão particulares que as fariam distintas das demais? Existiria um modo de pensar especificamente "oral"? De que "oralidade" se está falando? As tipificações realizadas pelos autores não provocariam uma dicotomia entre o oral e o escrito, que não corresponderia à grande parte das realidades?

Ong ( 1998 ) estabelece uma distinção entre o que denomina "oralidade primária" e "oralidade secundária". A primeira refere-se à oralidade das culturas intocadas pelo letramento ou por qualquer conhecimento da escrita ou da imprensa ou, ainda, a das pessoas totalmente não familiarizadas com a escrita. Por sua vez, a "oralidade secundária" refere-se à atual cultura de alta tecnologia, em que uma nova oralidade é sustentada pelo telefone, rádio, televisão e outros meios eletrônicos que, para existirem e funcionarem, dependem da escrita e da imprensa. Segundo Ong, na atualidade, não existe cultura de oralidade primária no sentido estrito, na medida em que todas as culturas conhecem a escrita e têm alguma experiência de seus efeitos.

Zumthor (1993), por sua vez, distingue três tipos de oralidade. A primeira, que denomina "primária e imediata", não estabelece contato algum com a escrita, encontrando-se apenas "nas sociedades desprovidas de todo sistema de simbolização gráfica, ou nos grupos sociais isolados e analfabetos" (p. I 8). Em segundo lugar, haveria uma "oralidade mista" em que o oral e o escrito coexistem, mas a influência do escrito "permanece externa, parcial e atrasada" (p. I 8). Esse tipo de oralidade procederia de uma "cultura 'escrita' ". Finalmente, o autor denomina "oralidade segunda" aquela que é característica de uma "cultura 'letrada' " e se "recompõe com base na escritura num meio onde este tende a esgotar os valores da voz no uso e no imaginário" (p. I 8). Esses tipos de oralidade variam, segundo Zumthor, de acordo não somente com as épocas, mas com as regiões, as classes sociais e também com os indivíduos.

Cook-Gumperz e Gumperz (1981) identificam três grandes momentos na história humana, quando se enfoca a relação entre oralidade e escrita. $\bigcirc$ primeiro teria se caracterizado por uma grande distância entre oralidade e es- 
crita, já que somente um pequeno grupo de pessoas, nessa fase, tinha acesso à alfabetização. Para os autores, até aproximadamente o século passado, o letramento tinha um status de "habilidade artesanal", na medida em que estava confinado em grupos privilegiados relativamente pequenos. Além disso, os materiais escritos eram caros e de difícil obtenção. Os autores se referem, por exemplo, para ilustrar esse momento, ao fato de os estilos literários serem gramatical e estilisticamente bem diferentes do idioma falado cotidianamente. Um outro exemplo citado pelos autores é o do latim: até o final da Idade Média, na Europa, era uma língua para a escrita, diferentemente da expressão oral. Nesse primeiro momento, a aprendizagem das habilidades letradas estava mais próxima de formas de contato pessoais, familiares e de processos de socialização informais do que de formas de aprendizagem sistematizadas em currículos formais.

Em uma segunda fase, a escrita passou a ser vista, predominantemente, como um registro da oralidade. Nesse momento, as narrativas orais passaram a ser divulgadas maciçamente pela escrita. Esse movimento caracterizaria uma proximidade entre a oralidade e a escrita. Com a industrialização, a urbanização, a emergência das camadas médias e a instituição de formas democráticas de participação política, as diferenças entre as linguagens cotidianas e as tradições literárias começaram a desaparecer. Esse processo vinha-se delineando desde a Reforma Protestante, na Europa, com a difusão maciça da leitura da Bíblia. Essas novas formas de linguagem passaram a ser sinônimos, para CookGumperz e Gumperz ( 198 I), de uma nova cultura urbana nacional. Apareceram as gramáticas impressas, os manuais de estilo, os dicionários e as enciclopédias. Além disso, o jornalismo se desenvolveu e, nas últimas décadas do século XIX, surgiram novas formas de novelas populares. Para os autores, a principal função da literatura para o público de massa, inicialmente, foi o entretenimento. A leitura substituiu a audiência da performance oral e a escrita foi utilizada para fazer listas, cartas etc. As atividades literárias, nesse momento, podem ser vistas como uma extensão dos usos da fala. Nesse sentido, a escrita não estava ainda fortemente associada às características de descontextualização a ela atribuídas na contemporaneidade. Até o início deste século, a educação popular, para Cook-Gumperz e Gumperz (|98|), esteve concentrada nas habilidades básicas de leitura, escrita e aritmética, mantendose afastada das escolas secundárias e das universidades, sistemas de ensino 
associados à elite. Para a maioria da população, o letramento não era vital para a sobrevivência econômica.

Em um terceiro momento, ainda segundo os autores, teria havido um novo afastamento entre oralidade e escrita, na medida em que esta última passou a assumir um outro aspecto, tornando-se burocratizada. Nessa fase, a escola desempenhará um papel fundamental. A nova configuração societária trazida pelo desenvolvimento tecnológico, pelas burocracias e pelas regulamentações governamentais exigiu novas formas de comunicação, fundamentalmente dependentes da palavra escrita. As funções do letramento se transformaram, a partir dos requisitos impostos pela especialização técnica nos diversos domínios da vida humana. As mudanças atingiram também, desse modo, os sistemas de educação, delegando novas funções para a escola, que se tornaram ao mesmo tempo agentes de socialização e instrumentos quase exclusivos de seleção de oportunidades econômicas. As sociedades modernas, para os mesmos autores, ao mesmo tempo em que tornaram o letramento essencial para a sobrevivência econômica, incrementaram novamente a dicotomia entre fala e escrita.

A hipótese básica desses estudos sobre os efeitos da escrita, da imprensa e, mais recentemente, das tecnologias eletrônicas nas diversas sociedades é, segundo Havelock ( 1988), a de que, se "o meio é a mensagem", esta última sofre transformações em conseqüência do processo em que foi transmitida/ recebida. Nesse sentido, as culturas orais e as culturas letradas se diferenciariam fundamentalmente na medida em que seus modos de transmissão e apropriação da linguagem são distintos. A partir desse pressuposto básico, muitos estudos buscaram encontrar aspectos que pudessem caracterizar as culturas de oralidade primária, distinguindo-as das demais, inclusive nos modos de pensamento que Ihes seriam inerentes.

Segundo Ong, nas culturas de oralidade primária, as palavras, que são sons - na medida em que não possuem suporte visual - estão associadas diretamente a ocorrências, eventos e acontecimentos. Para o autor, o som tem uma relação com o tempo diferente das outras sensações humanas por ser evanescente. Ong retoma Malinowski que, em suas pesquisas nas sociedades tribais, constatou que a linguagem, entre os "primitivos", é muito mais um modo de ação do que uma maneira de referendar o pensamento. Nesse sentido, nas culturas orais, as palavras têm um grande poder sobre as coisas, um poder 
relacionado à magia: muitas palavras são consideradas tabu, associadas, muitas vezes, ao azar ou à sorte.

Como já foi referido, segundo alguns pesquisadores, as diferentes culturas gerariam modos de pensar específicos de acordo com o papel que nelas ocupassem as expressões oral e escrita. Desse modo, haveria, pelo menos, os modos de pensar oral, quirográfico (ligado ao manuscrito, uma scribal culture), tipográfico (uma print culture) e eletrônico. O pressuposto básico que orienta essas investigações é o de que a linguagem determina o pensamento: as pessoas pensam de acordo com a maneira que possuem para se expressar naquela cultura. Ong é um dos autores que busca levantar hipóteses na direção de generalizar aspectos da "psicodinâmica das culturas de oralidade primária", reconhecendo a quase impossibilidade de realizar essa tarefa, na medida em que, nesse caso, não é possível trabalhar com dados empíricos e é difícil, para uma pessoa que vive em uma sociedade letrada, imaginar em que se constitui uma sociedade sem escrita. $\bigcirc$ autor enumera, então, diversas características que expressariam modos de pensamento tipicamente orais. Inicialmente, o pensamento oral seria mais aditivo do que subordinativo. Para Ong, isso não significa que o modo de pensar oral seja incapaz de estabelecer relações, por exemplo, de causa e conseqüência, mas que a utilização de aditivos constitui a forma principal de expressão do pensamento.

modo de pensar oral seria também mais agregativo do que analítico. Essa característica é expressa, por exemplo, na grande carga de epítetos ("Odisseu, o astuto", por exemplo) e outras fórmulas (como provérbios e frases feitas) que caracterizam a expressão oral e que são rejeitadas pela "alta" literatura, por provocarem, em sua avaliação, redundância e monotonia na linguagem. Para Ong, na medida em que as expressões agregativas são utilizadas, resta pouco espaço para o questionamento das adjetivações: a opinião já viria avalizada, cristalizando, de certo modo, o pensamento. Ong afirma, ainda, que o pensamento oral é redundante e pouco original. A repetição do "já-dito" pelo falante atende a certas expectativas do ouvinte em relação aos mesmos temas e às mesmas formas. Para o autor, a eliminação da redundância demanda uma tecnologia que implique a utilização de um espaço de tempo maior: a escrita. Com ela, a mente é forçada a tornar o pensamento mais lento, oportunizando a reorganização da linguagem, eliminando as repetições desnecessárias. Essa característica estaria, para o autor, mais presente quando o falante se encontra 
diante de uma grande audiência do que em situações de conversações face a face. Ong argumenta que, em uma apresentação oral, quando há uma pausa no pensamento do falante, é mais fácil para ele, e mais compreensível para os ouvintes, repetir a idéia pronunciada anteriormente do que parar e apenas dar continuidade ao discurso com a emergência da idéia seguinte. Como quarta característica do pensamento oral, Ong aponta o seu caráter conservativo e tradicionalista. Nas sociedades orais, há um grande investimento de energia na transmissão da cultura de geração a geração. $O$ conhecimento tem que ser continuamente repetido para que as novas gerações possam, "arduosamente", aprender. Em conseqüência dessa necessidade, as sociedades orais geram um padrão de pensamento altamente tradicionalista e conservativo, inibindo, assim, a experimentação intelectual:

O conhecimento exige um grande esforço e é valioso, e a sociedade tem em alta conta aqueles anciãos e anciãs sábios que se especializam em conservá-lo, que conhecem e podem contar as histórias dos tempos remotos. Pelo fato de armazenar o conhecimento fora da mente, a escrita - e mais ainda a impressão tipográfica - deprecia as figuras do sábio ancião, repetidor do passado, em favor de descobridores mais jovens de algo novo. (Ong, 1998, p.52)

Desse modo, para o autor, as culturas orais não gastam energias com novas especulações: a mente é utilizada predominantemente para conservar. Para ele, esse aspecto não denota falta de originalidade. A originalidade não consiste, no interior dessas culturas, na criação de novas histórias, mas na maneira pela qual as velhas narrativas são manejadas em interação com as audiências, como ainda será discutido: "... a cada narração, deve-se dar à história, de uma maneira única, uma situação singular, pois nas culturas orais o público deve ser levado a reagir, muitas vezes intensamente" (Ong, 1998, p.53). Os narradores sempre introduzem novos elementos nas histórias tradicionais: "Na tradição oral, haverá tantas variantes menores de um mito quantas forem as repetições dele, e a quantidade de repetições pode aumentar indefinidamente" (Ong, 1998, p.53).

O pensamento oral caracteriza-se também, segundo Ong, por sua proximidade com o "mundo vital". Nas culturas orais, o conhecimento é conceitualizado e verbalizado sempre em referência, maior ou menor, à experiência humana. Mesmo o que seria estranho à vivência imediata é assimila- 
do, transformado, adaptado às interações e às necessidades concretas das pessoas. Nesse sentido, a própria aprendizagem ocorre por meio da observação e da prática e, minimamente, pela explanação verbal e pela recorrência a conceitos abstratos. $\bigcirc$ tom predominantemente emocional também caracterizaria o pensamento oral, na avaliação de Ong. A memória oral trabalha com narrativas míticas, personagens fortes, cujas mortes em geral são monumentais, memoráveis e comumente públicas. A heroicização dos personagens não se baseia, para o autor, em razões românticas ou mesmo didáticas, mas corresponde à necessidade de organização da experiência daquela sociedade de uma forma permanentemente memorável. O herói e o anti-herói, nesse sentido, servem a uma função específica na organização do conhecimento no mundo oral. A narrativa é marcada freqüentemente, desse modo, pela descrição entusiasmada da violência física. A própria especificidade da expressão oral contribui para que essa característica seja marcante: a comunicação verbal está sempre envolvida em relações interpessoais caracterizadas tanto pela atração quanto pelos antagonismos. Em conseqüência dessa característica, há uma tendência à polarização das narrativas: de um lado, encontram-se o bem, a virtude e os heróis; de outro, o mal, o vício e os vilões. Referindo-se ao trabalho de Abrahams, Ong afirma:

Provérbios e enigmas não são usados simplesmente para armazenar conhecimento, mas para envolver as pessoas em um combate verbal e intelectual: dizer um provérbio ou um enigma desafia os ouvintes a superá-lo com um outro mais adequado ou oposto. (1998, p.55)

O pensamento oral é, ainda, mais empático e participativo do que objetivamente distanciado. Para Ong, assim como para diversos outros pesquisadores, a escrita separa o conhecedor do conhecido e estabelece condições de objetividade, como se discutirá adiante. Referindo-se ao trabalho de Havelock, afirma Ong: "Para uma cultura oral, aprender ou saber significa atingir uma identificação íntima, empática, comunal com o conhecido, 'deixar-se levar por ele' " (1998, p.57). O equilíbrio caracterizaria também, na perspectiva de Ong, o pensamento oral. As sociedades orais organizam-se muito em função do presente, apagando as memórias que não têm relevância para a vivência imediata, o que contribuiria para o equilíbrio societal. O significado de cada palavra é 
controlado pela "ratificação semântica direta", na expressão de Goody e Watt (apud Ong, 1998), isto é, pelas situações reais de vida em que a palavra é usada. $O$ pensamento oral não está interessado em definições abstratas: as palavras adquirem seu significado no contexto em que são expressas, incluindo os gestos, as inflexões vocais, a expressão facial etc.

Finalmente, Ong identifica uma última característica do pensamento oral, de certo modo já referida: o fato de ser mais situacional e concreto do que abstrato. As culturas orais tendem a usar conceitos operacionais e padrões de referência que se constituem, minimamente, em abstrações. Essa característica foi bastante explorada em pesquisa realizada por Luria, ainda nos anos 30. Embora as culturas orais produzam organizações de pensamento e experiência "inteligentes", jogos intelectuais, classificações, definições, categorizações, processos formais, descrições e outros elementos constitutivos da lógica formal típicos das sociedades letradas, não funcionam entre as pessoas de oralidade primária. Cook-Gumperz e Gumperz (1981), também baseados no trabalho de Luria, afirmam que existem diferentes estratégias de racionalização. Ao contrário das pessoas letradas, as não letradas, no geral, não descontextualizam os problemas: o modo de racionalidade das primeiras seria "teórico", enquanto o das segundas "empírico".

As especificidades das sociedades de oralidade primária e dos modos de pensamento orais determinam, também, como já foi referido, maneiras particulares de transmissão do conhecimento e da cultura. Essa questão também tem sido objeto de vários estudos. Para Havelock, a transmissão da cultura, quando se toma um paradigma teórico da antropologia, pode ser descrita da seguinte maneira:

...assim como os nossos genes armazenam informações codificadas que guiam o organismo em desenvolvimento, desde a concepção até a morte, um armazenamento transferido de geração para geração, no nível das culturas sociais, necessário para que sociedades existam e usufruam de suas próprias formas de continuidade orgânica, tem que dispor a informação acumulada para que esta possa ser reutilizada. $O$ método mais usado para isso é o método lingüístico. Isto pode ser facilmente constatado nas informações documentadas que abrangem os conhecimentos do direito e da literatura, da ciência e da tecnologia, com as quais nós nos educamos, e a partir das quais adquirimos nossos 
valores e atitudes, à medida que recebemos, reutilizamos e adicionamos a estes conhecimentos outras informações. (1988, p. 128 , tradução nossa)

A partir dessa idéia mais geral, o autor descreve como se dá, então, esse processo em culturas não letradas:

De que forma podemos obter os mesmos tipos de resultados em uma cultura não letrada? Nessas culturas, o armazenamento e a transmissão entre as gerações podem ser feitos apenas por meio de memórias individuais. A informação lingüística pode ser incorporada numa memória transmissível, se obedecer a duas leis de composição: tem que ser rítmica e mítica... ( 1988 , p. I 28, tradução nossa)

Havelock ( 1988 ) esclarece que utiliza a palavra "mítico" no sentido a ela atribuído pelos gregos, incluindo sua expressão por meio do conto e também de ditados, que posteriormente foram elaborados. Os "pedaços" da informação cultural são, nessas culturas, governados pela sintaxe do conto, que descreve principalmente uma ação performada por um agente mais do que por uma lei, princípio ou fórmula: "O épico deve contar uma história em que os personagens sejam pessoas fazendo coisas ou sofrendo o efeito delas, com uma notável ausência de pensamento abstrato. Pode-se refletir, mas sempre como ser humano, e nunca como filósofo, intelectual ou teórico" (Havelock, 1995, p.30). Segundo o autor, as culturas orais não se satisfariam se a transmissão da cultura se desse apenas através de um conjunto de máximas e ditados ou mesmo de pequenas histórias separadas. As pessoas que vivem em culturas de oralidade primária necessitam de uma grande história - os épicos nacionais dentro da qual valores, atitudes, normas e comportamentos são transmitidos:

Eles relatam, ilustram e sugerem, indiretamente através da narrativa, os costumes, modos, leis, religião e formas de governo de um povo. Esses povos confiam a informação e a recitação desses textos épicos a trovadores profissionais e são continuamente instruídos por estes cantores à medida que ouvem os poemas recitados e são encorajados a repeti-los. (Havelock, 1988, p. 1 29, tradução nossa)

Para Havelock, as epopéias gregas, que podem ser consideradas "imensos repositórios de informação cultural", tinham, além do objetivo de 
armazenamento de informações, aquele de entretenimento. Essa questão tem implicações no trabalho do pesquisador:

Com esses conceitos em mente, o antropólogo que registra os mitos e as histórias tribais buscará uma distinção entre material funcional memorizado para o uso social e as histórias e canções improvisadas para o mero entretenimento. (1995, p.33)

Nas culturas orais, então, os ditados não são um fenômeno ocasional, mas, de maneira incessante, constituem a substância mesma do pensamento. Para Ong (1998), o pensamento oral é impossível sem eles porque consiste neles. Nesse sentido, provérbios e ditados não são meras "decorações jurisprudenciais", mas constituem a própria lei.

De modo semelhante à Havelock ( 1988, 1995), para Ong ( 1 998), o fato de, em uma cultura oral, as palavras estarem restritas ao som não determina apenas os modos de expressá-las, mas também os processos de pensamento e de estocagem do conhecimento: "sabemos o que podemos recordar" (p.44). Nessas culturas, um interlocutor é virtualmente essencial: afinal, é difícil falar para si próprio durante muito tempo. O pensamento contínuo em uma cultura oral está atado, assim, à comunicação. Sobre o processo de memorização nas culturas orais, diante da impossibilidade de registrar o conhecimento adquirido por escrito, Ong afirma que:

Numa cultura oral primária, para resolver efetivamente o problema da retenção e da recuperação do pensamento cuidadosamente articulado, é preciso exercêlo segundo padrões mnemônicos, moldados para uma pronta repetição oral. O pensamento deve surgir em padrões fortemente rítmicos, equilibrados, em repetições ou antíteses, em aliterações e assonâncias, em expressões epitéticas ou outras expressões formulares, em conjuntos temáticos padronizados (...), em provérbios que são constantemente ouvidos por todos, de forma a vir prontamente ao espírito, e que são eles próprios modelados para a retenção e a rápida recordação - ou em outra forma mnemônica. (1998, p.45)

Ong, referindo-se ao trabalho de Lord, comenta os processos educativos existentes entre os próprios bardos: 
Com base nessas entrevistas e na observação direta, sabemos como os bardos aprendem: ouvindo, durante meses e anos, outros bardos que nunca cantam uma narrativa do mesmo modo duas vezes, mas que usam repetidas vezes as fórmulas-padrão relativas aos temas-padrão. (1998, p.73)

A narrativa e o acompanhamento musical são memorizados por aprendizes, que começam ainda muito novos, trabalhando com um mestre oral. Os mestres (não há nenhum vivo) encarregam-se de treinar seus aprendizes na recitação literal do cântico por meio de uma disciplina rigorosa durante vários anos e conseguem resultados notáveis, embora eles próprios façam, nas suas próprias recitações, mudanças das quais não se dão conta. (1998, p.76-77)

A aprendizagem nas culturas de oralidade primária não ocorre, pois, pelo disciplinamento imposto pelo hábito de "estudar", mas predominantemente pela imitação:

Eles aprendem pela prática - caçando com caçadores experientes, por exemplo, pelo tirocínio, que constitui um tipo de aprendizado; aprendem ouvindo, repetindo o que ouvem, dominando profundamente provérbios e modos de combinálos e recombiná-los, assimilando outros materiais formulares, participando de um tipo de retrospecção coletiva - não pelo estudo no sentido restrito. (1998, p. | 7)

Nessas culturas, pois, a repetição e o recurso à memória constituem a base dos processos de transmissão do conhecimento. Egan (1987) mostra como, nesses espaços, a educação é "...fundamentalmente uma questão de expor os jovens constantemente a padrões encantadores de som até que suas mentes vibrem, até que entrem em harmonia com as instituições de suas culturas" (p.45I).

Em tais culturas, o aprendizado se dá, em grande medida, somaticamente: todo o corpo, mediante movimentos rítmicos, é utilizado nos processos de memorização. Os cantadores/narradores populares, muitas vezes, se utilizam de um instrumento simples, como o tambor, para reforçar o ritmo da narrativa, contribuindo para introduzir nos ouvintes o "encantamento" do som, deixando-os em um estado de semi-hipnose, marcado pelo prazer e pelo relaxamento: 
O processo de cativar a platéia, de deixar registrado nela a realidade da estória, é uma das principais características da educação nas culturas orais. As instituições sociais nessas culturas sobrevivem, em sua maioria, graças ao som, ao que a palavra falada ou cantada pode fazer para converter indivíduos a determinadas crenças, expectativas, papéis e comportamentos. (Egan, 1987, p.45। , tradução nossa)

De fato, a memória oral tem um grande componente somático. A própria composição oral tem sido associada a uma atividade manual: "A palavra oral, como já observamos, nunca existe num contexto puramente verbal, como ocorre com a palavra escrita. As palavras proferidas são sempre modificações de uma circunstância total, existencial, que sempre envolve o corpo" (Ong, 1998, p.81).

Muitos estudos realizados no campo da oralidade e letramento afirmam que, com a introdução da escrita nas culturas de oralidade primária, ocorreram transformações profundas em todas as dimensões da vida social e cultural. Alguns autores, como Goody (1977), chegam a considerar o advento da escrita como um fato divisor entre o pensamento "selvagem" e o pensamento "civilizado".

Para muitos pesquisadores, como Havelock (1988), quando os estudos se referem aos impactos trazidos pela introdução de sistemas de escrita, estão aludindo ao alfabeto grego. Segundo o autor, a invenção dessa tecnologia constituiu uma etapa decisiva na história ocidental, podendo ser considerada uma grande revolução, o apogeu de um processo progressivo. Havelock ( 1988 ) chega a afirmar que a história da mente e da linguagem humanas pode ser dividida em duas grandes épocas: a pré-alfabética e a pós-alfabética. $\bigcirc$ nascimento da história teria se dado com a invenção do alfabeto grego: "Em particular eu estou me referindo ao nascimento da história e da literatura histórica, que emergiram no final do século em Atenas" (p. I33).

Para Havelock, desse modo, o momento não representou somente uma adaptação do alfabeto fenício, mas constituiu um ato de abstração, na medida em que os gregos utilizaram o novo instrumento para simbolizar sons existentes analiticamente como objetos mentais, mas que não existiam empiricamente como os sons falados. Para o autor, o alfabeto grego trouxe, pelo menos, quatro efeitos: tornou fluente o reconhecimento das palavras; tirou a pressão sobre a memória, característica das culturas orais; substituiu o auditivo pelo 
visual; e tornou a linguagem um artefato, uma coisa, um objeto de estudo - a gramática pôde ser inventada a partir de então. Para o autor, o alfabeto afetou a estrutura da linguagem e do pensamento, ao substituir o concreto pelo abstrato. Nesse sentido, o letramento não criou uma cultura, mas transformou profundamente, no decorrer de séculos, a que foi herdada.

Na mesma direção, Ong (1986) afirma que nenhum outro sistema de escrita reestruturou o mundo humano de maneira tão drástica quanto a escrita alfabética. Para o autor, assim como para outros pesquisadores, a escrita deve ser vista como qualquer outra tecnologia, na medida em que provoca mudanças no pensamento, reestruturando-o, e na relação das pessoas com o mundo. As tecnologias, além de constituírem ajudas exteriores ao homem, contribuem também para uma transformação interior da consciência. Ainda segundo Ong, as tecnologias são artificiais, mas, paradoxalmente, a artificialidade é natural para os seres humanos. A tecnologia, se for propriamente interiorizada pelas pessoas, não degrada a vida, mas, ao contrário, a desenvolve: "O uso de uma tecnologia pode enriquecer a mente humana, engrandecer o espírito, libertá-lo, intensificar sua vida interior" (Ong, 1986, p.33).

Os autores buscam também, nessa perspectiva, apontar as características e os principais efeitos da escrita. Ong afirma que a conseqüência principal e mais geral da introdução da escrita foi o que denominou "separação". Inicialmente, a escrita separa o conhecido do conhecedor, promovendo a "objetividade" da linguagem: entre esses dois pólos, a escrita interpõe um objeto tangível, o texto. A imprensa e os meios eletrônicos continuaram, de forma intensificada, esse processo de separação. Além disso, para ele, ao contrário do que ocorre nas culturas orais, a escrita separa a interpretação do dado. Para exemplificar essa questão, o autor argumenta que as pessoas que vivem em culturas de oralidade primária apresentam dificuldades em entender o que os letrados denominam "repetição palavra por palavra". Pesquisas realizadas mostraram que elas, quando demandadas a repetir exatamente o que haviam dito, fazem, na verdade, uma interpretação do que inicialmente disseram, acreditando que houvessem repetido.

Segundo Ong (1998), a escrita distancia, ainda, a palavra do som: a evanescência da oralidade dá lugar ao espaço visual da escrita. A quarta "separação" relacionada pelo autor diz respeito ao distanciamento, no tempo e no espaço, que ocorre, na escrita, entre a fonte da comunicação (o escritor) e o 
recipiente (o leitor). Na comunicação oral, por sua vez, a fonte (o falante) e o recipiente (o ouvinte) estão necessariamente presentes. A escrita distancia também a palavra do contexto existencial. Para Ong (1986), o contexto da escrita inclui apenas outras palavras, enquanto na expressão oral, como se viu, as relações pessoais fazem parte da comunicação. Na enunciação oral, o contexto sempre inclui mais do que palavras: a maior precisão das enunciações dáse mediante elementos não verbais, o que torna os significados situacionais. A escrita se constituiria, então, em um discurso autônomo, fruto do pensamento analítico: a comunicação, por esse meio, está menos embebida das pressões sociais do momento imediato.

A escrita separa também, para o autor, o passado do presente. Nas culturas de oralidade primária o passado é utilizado para explicar o presente e aquilo que não serve a esse propósito deve ser apagado da memória. Desse modo, na avaliação de Ong ( 1998), há uma certa homogeneização ou aproximação do passado em referência ao presente, enquanto nas culturas escritas, o passado parece ter validade por si mesmo, conservando-se distante do momento atual. Ong (1986) argumenta ainda que a escrita separa a administração - civil, religiosa, comercial, entre outras - de outros tipos de atividades sociais. Segundo o autor, a "administração" é algo desconhecido nas culturas orais, em que os líderes interagem de maneira concreta com o resto da sociedade. A escrita permite também a separação da lógica, entendida como a estrutura do discurso, da retórica, esta compreendida como o discurso socialmente efetivo.

Para Ong (1986), a escrita separa igualmente a aprendizagem acadêmica da sabedoria, tornando possível a organização de estruturas abstratas de pensamento independentemente de seus atuais usos ou de sua integração no mundo vital. Inicialmente, quando as culturas se encontram em processo de assimilação da escrita, ainda tendem a colocar ditados de sabedoria em seus textos. No entanto, os tornam desnaturalizados, na medida em que foram, na verdade, transformados pela nova tecnologia, não funcionando do mesmo modo que nas culturas orais. A escrita divide também, segundo o autor, a sociedade entre a 'alta' linguagem, completamente controlada pela escrita, e a 'baixa' linguagem, controlada pela oralidade, com a exclusão da escrita. A escrita diferencia, do mesmo modo, o "grafoleto" (ou dialeto construído com base na escrita) de outros dialetos, tornando o primeiro um dialeto de importância 
e efetividade completamente diferentes daqueles que continuam orais. A escrita distancia de forma mais evidente e efetiva sua própria forma, tornandose mais abstrata, mais afastada da palavra sonora. Finalmente, segundo o autor, a escrita separa o ser do tempo. As pessoas que vivem em culturas de oralidade primária podem ser sábias e dar certas explicações para as coisas, mas a elaboração e o estabelecimento de seqüências exatas de causa e efeito requeridos pela filosofia e pelo pensamento científico são desconhecidos entre elas, incluindo os primeiros gregos antes do desenvolvimento do seu primeiro alfabeto. Com a escrita interiorizada, a verbalização deixa de ser, predominantemente, uma estrutura de ação para tornar-se uma estrutura de "ser" (Ong, 1986).

Alguns outros contrastes são indicados pelos autores quando analisam as relações entre oralidade e escrita. Para Ong (1998), por exemplo, a escrita está atada ao espaço, enquanto a oralidade está presa ao tempo, em conseqüência da presença ou ausência de suportes materiais para expressar a linguagem: "As palavras escritas são resíduos. A tradição oral não tem tais resíduos ou depósitos" (Ong, 1998, p. 17). A escrita, ao contrário da linguagem oral, é linear e completamente artificial. Para o autor, enquanto a oralidade é natural, não existe nenhuma maneira de se escrever "naturalmente": o processo de colocar a expressão oral em sua forma escrita é conscientemente governado por procedimentos articulados (Ong, 1986). Para Ong (1998), as estruturas orais freqüentemente se utilizam mais de elementos pragmáticos (a palavra como ação); as estruturas quirográficas (ou manuscritas) de elementos sintáticos; e o discurso tipográfico desenvolve uma gramática mais elaborada, fixada e dependente da estrutura lingüística.

Assim como as sociedades orais possuem formas específicas de transmissão do conhecimento, com a introdução de sistemas de escrita, novas formas de transmissão, aprendizagem e memorização da cultura foram também introduzidas.

Com a invenção do alfabeto grego, segundo Havelock (1988), foram criadas as condições para que o letramento se tornasse popular, uma vez que poderia ser aprendido pela maioria da população. No entanto, a sociedade grega não se tornou letrada repentinamente. Dois fatores são apontados pelo autor como limitadores do processo de generalização: não havia nem suportes materiais, nem uma tecnologia específica para que a escrita pudesse ser 
ensinada - os arranjos institucionais necessários a esse propósito não existiam. A educação musical grega vai realizar essa tarefa: os poetas continuaram, por mais de dois séculos, a preservar e a transmitir as tradições da sociedade, até que a possibilidade de documentar a poesia, através da escrita, se tornasse real. Mesmo depois da introdução do alfabeto entre os gregos, até que um público leitor começasse a efetivamente existir e pudesse compreender as novas formas de composição escrita, os poetas permaneceram ainda essencialmente orais. Desse modo, durante muito tempo, o alfabeto grego foi usado primordialmente para gravar e perpetuar o que havia sido composto oralmente:

Os poetas eram chamados para dar continuidade às funções didáticas de Homero, principalmente aquelas exemplificadas na dramaturgia de Atenas, na qual os mitos tradicionais, ou seja, as estórias recontadas oralmente, são continuamente exaltados em várias versões, para divertir mas também para instruir. (Havelock, 1988, p.130, tradução nossa)

Nesse momento, o alfabeto, embora com uma extensão limitada, foise tornando um instrumento de alguns governos, leis e atividades econômicas. Somente na última metade do século $V$, segundo Havelock (I988), é que há evidências de que sua aplicação começou a se multiplicar. Esse entrecruzar de expressões - oral e escrita - gerou tensões naquele momento histórico: aos poucos, o olho invadiu a província do ouvido e o leitor o espaço do ouvinte. Assim, é que Havelock afirma que talvez a grande divisão da cultura grega tenha tido início na época de Platão quando, ao poucos, a literatura metrificada e recitada deixou de ser o principal meio de transmissão do conhecimento, o que caracterizava a sociedade como "oralista", e a prosa passou a se tornar o veículo de "reflexão séria, pesquisa e registro":

Isso significava que a língua grega antes de Platão, mesmo quando escrita, era composta segundo as regras da composição oral e tinha de suportar o fardo da instrução pessoal e da orientação social que Platão agora se propunha a oferecer em seus diálogos. (1995, p.29)

As novas formas de documentação e registro foram, então, pouco a pouco, sendo utilizadas: 
Inicialmente, o alfabeto foi usado para registrar a linguagem oral como havia sido antes organizada para a memorização pelo drama, pela epopéia e pela lírica. A revolução conceitual teve início quando se percebeu que o registro oral dos sons lingüísticos podia ser armazenado de maneira nova, não mais dependente dos ritmos empregados para a memorização. Esse registro podia se tornar documento, um conjunto permanente de formas visíveis, não mais construído por fugazes vibrações do ar, mas por formas que podiam ser conservadas até um posterior resgate, ou mesmo esquecidas. (Havelock, 1995, p.32)

Esse processo duraria, ainda, séculos:

A palavra rítmica como armazenamento e veículo de informação lentamente foi-se tornando obsoleta. (...) A palavra poética, durante muito tempo, ainda conservou um papel funcional, ou seja, didático, na sociedade européia. Eneida, Divina Comédia e Paraíso Perdido são provas da permanência dessa função. Somente no século $X X$, pode-se afirmar, a lógica da transferência da memória para o documento foi plenamente realizada. A nossa é, na verdade, uma cultura prosaica. (Havelock, 1995, p.32)

Com a generalização da escrita, outras conseqüências puderam ser observadas em diversas sociedades. Para Cook-Gumperz e Gumperz (| 98|), o processo de aquisição do conhecimento passou a requerer uma separação entre sua transmissão e as práticas cotidianas. $\bigcirc$ conhecimento acumulado e a vida diária tornaram-se separados. Nesse processo, grupos específicos foram emergindo e se especializando em preservar, editar e interpretar a informação escrita, utilizando, para isso, uma linguagem criada que se diferenciava daquela utilizada na vida cotidiana. $\bigcirc$ conhecimento tornou-se, então, aos poucos, descontextualizado e formalizado, e instituições foram criadas especialmente para transmiti-lo, de geração em geração: as escolas. Segundo Ong, o comportamento "estudar" só surge depois da introdução dos sistemas de escrita:

Todo pensamento, inclusive nas culturas orais primárias, é de certo modo analítico: ele divide seu material em vários componentes. Mas o exame abstratamente seqüencial, classificatório e explicativo dos fenômenos e de verdades estabelecidas é impossível sem a escrita e a leitura. Os seres humanos, nas cultu- 
ras orais primárias, não afetados por qualquer tipo de escrita, aprendem muito, possuem e praticam uma grande sabedoria, porém não "estudam". (I998, p. |7)

Além dos trabalhos que buscam investigar as relações entre oralidade e escrita em perspectivas mais próximas da História, da Antropologia, da Sociologia e da Filosofia, como os que foram aqui sucintamente referidos, muitas pesquisas focalizaram as diferenças lingüísticas entre essas duas formas de linguagem. Destacam-se, nessa perspectiva, os trabalhos de Tannen (ver, por exemplo, 1985), Chafe (1985), Smith (1994), Cook-Gumperz e Gumperz ( 198 I). Muitos deles também enfatizam os contrastes existentes entre oralidade e escrita. Outros buscam, mediante abordagens alternativas, relativizar as grandes dicotomias entre oral e escrito presentes em muitos trabalhos ${ }^{10}$.

\section{Observações críticas acerca dos estudos sobre culturas orais e escritas}

Muitos pesquisadores têm afirmado que as relações entre oralidade e escrita são muito mais complexas do que alguns estudos podem fazer supor. As grandes dicotomias estabelecidas entre oral e escrito têm sido, para eles, incapazes de explicar as intrincadas relações existentes entre as diferentes formas de linguagem, as características e os modos de pensamento em culturas diversas. Afirmações como as que sustentam que somente os letrados possuem capacidade de abstração; que a introdução da escrita e, mais tarde, da imprensa, constituíram marcos divisores na história da humanidade; ou, ainda, que as culturas podem ser divididas em "orais" e "escritas", sem que seja considerada a coexistência do oral e do escrito na mesma época e no mesmo lugar, têm sido problematizadas e investigadas com maior profundidade em vários estudos.

Para Graff (1987), por exemplo, é certo que a penetração da escrita em culturas nativas orais tende a causar profundas transformações sociais, religio-

10. Para uma síntese desses estudos, ver Akinnaso (1982). $\bigcirc$ autor, nesse artigo, realiza uma síntese dos resultados de pesquisas, notadamente empíricas, nas diversas áreas que investigam as relações entre as linguagens oral e escrita e suas diferenças léxicas e sintático-semânticas, destacando-se a sociolingüística, a análise do discurso e os estudos sobre letramento, a partir dos anos 1920, em língua inglesa. O autor enfatiza, nessa revisão, as bases teóricas e metodológicas dos estudos e suas implicações pedagógicas. 
sas, ideológicas, políticas, econômicas e culturais. $\bigcirc$ autor critica, no entanto, as grandes divisões tradicionalmente apontadas entre culturas orais e letradas em pesquisas realizadas nesse campo de estudos. Critica ainda a tendência normalmente observada de considerar a cultura da escrita como algo sempre positivo, muitas vezes diretamente associado às necessidades vitais de pessoas e sociedades "modernas" e "desenvolvidas". Para o autor, na verdade, é muito difícil ou quase impossível conceituar "cultura escrita”, a não ser que a definição seja considerada historicamente e, desse modo, contextualizada no tempo e no espaço. $\bigcirc$ autor argumenta que, se a história da cultura da escrita traz contradições interiores, suas conseqüências também serão contraditórias e não obedecem, como muitos estudos parecem crer, a uma linearidade evolutiva que resultaria no "progresso" de todos os povos. $\bigcirc$ autor demonstra, por exemplo, que a cultura escrita tem diferentes significados, que variam em razão de seus modos de aquisição, papéis e usos, para membros de diferentes continentes, regiões, estados ou mesmo grupos. Nesse sentido, aponta para a necessidade de se realizarem pesquisas mais cuidadosas, tomando como sujeitos indivíduos, grupos, seus sistemas socioculturais e os impactos que trazem os modos de comunicação introduzidos, naquele contexto específico.

Desse modo, Graff (1987) busca desmistificar a idéia de que a cultura escrita estaria, como defendem diversos estudos, sempre associada ao crescimento econômico, à industrialização, à estabilidade política, à participação democrática, à urbanização, ao consumo e, ainda, à contracepção. Assim, o autor mostra que é um mito considerar que as pessoas letradas são sempre empáticas, inovadoras, cosmopolitas, urbanas e receptivas ao desenvolvimento tecnológico. Na mesma perspectiva, relativiza o papel atribuído normalmente à educação que, sob o ponto de vista do "mito do letramento", é capaz de, entre outras coisas, estimular o desenvolvimento econômico, prover as bases da democracia e unir e integrar as pessoas em torno de valores, instituições e linguagens comuns. Na visão do autor, embora a educação e o letramento se transformem ao longo do tempo, nem sempre as conseqüências a eles diretamente associadas ocorrem na mesma medida. Muitas das pesquisas que contribuem para ratificar o "mito do letramento" consideram, por exemplo, escolarização e habilidades/atitudes letradas como sinônimos. Na verdade, muitas das conseqüências atribuídas ao letramento são resultados da escolarização. Nesse sentido, Graff se refere aos estudos sobre o povo Vai, realizados por 
Scribner e Cole, em que pessoas escolarizadas e não escolarizadas foram comparadas em relação a certos tipos de comportamentos normalmente atribuídos às pessoas letradas. Os resultados mostraram que essas habilidades não são conseqüências do letramento em si mesmo, mas produtos da escolarização. É a escolarização institucional formal - e não o letramento em si - que enfatiza, em seus processos de aprendizagem, formulações gerais ou descrições/competências em sistemas simbólicos e abstratos. Na escola, o letramento tem um uso especial: a linguagem separa-se do contexto de ação. Para Graff (1987), o viés letrado da escolarização é, também, um dos legados do letramento.

Em direção semelhante, Brian Street ( 1995) estabeleceu, para a análise da cultura escrita, os modelos autônomo e ideológico. No primeiro caso, o letramento, como um bem cultural, seria considerado bom em si mesmo, para todos, em qualquer lugar ou época, e capaz, por si mesmo, de modo independente dos contextos, de transformar os indivíduos e as sociedades; o analfabetismo, constituiria um mal que deveria ser extirpado. $\bigcirc$ modelo ideológico, por sua vez, não considera a cultura escrita um bem em si mesmo, mas um processo que está estritamente associado às condições/instituições socioculturais em um determinado contexto. Situadas entre autoridade/poder e resistência individual/criatividade, as práticas de letramento devem ser consideradas, para Street (1995) não somente aspectos da "cultura", mas também das estruturas de poder. Desse modo, o autor não considera a escrita como um divisor de águas entre dois tipos completamente diferentes de culturas: para ele, o oral e o escrito coexistem incessantemente, havendo um trânsito contínuo entre esses dois modos de expressão.

Street (1 995) faz críticas severas, nos níveis metodológico, empírico e teórico, a autores como Ong ( 1998), que colocam a escrita como o marco que dividiria as sociedades em dois estágios: de um lado, a mentalidade "pré-lógica", o mito e a incapacidade de abstração; de outro, a "lógica", a história, o desenvolvimento da ciência, da objetividade e do pensamento crítico '! Para Street ( I995), Ong (1998), em suas análises, não considera as condições socioistóri-

I।. Street chega a afirmar que os estudos de Ong têm pouco valor na investigação sobre as relações entre oralidade e letramento. 
cas concretas das diferentes culturas. Do mesmo modo, o autor critica as abordagens, como muitas que são realizadas na perspectiva lingüística, que consideram como contexto da prática de letramento apenas a situação específica em que ela ocorre, desconsiderando questões de caráter mais geral, como aspectos históricos, sociais, políticos, econômicos etc. Como abordagem alternativa, o autor sugere que sejam utilizadas as contribuições da análise do discurso e a abordagem etnográfica da antropologia.

Street (1995), ao criticar os estudos tradicionalmente realizados, enumera o que ele denominou "mitos do letramento" presentes nessa produção e que, por se constituírem em um a prioriem muitos estudos, impedem que investigações mais profundas sejam realizadas. Inicialmente, o autor identifica a noção de que o discurso escrito se torna significativo pela lexicalização e pela gramática, enquanto o discurso oral realiza essa tarefa por meio de padrões paralingüísticos. Essa concepção reiteraria a "grande divisão". Além disso, Street encontra cristalizada nesses estudos a noção de que o discurso escrito é "conectado" e "coesivo", enquanto o discurso oral é fragmentado e desconectado. Finalmente, identifica o mito de que a linguagem escrita deriva seu significado diretamente das próprias palavras escritas, enquanto a linguagem oral encontra-se mais "embebida" nas pressões sociais imediatas da comunicação face a face.

Outor, de forma semelhante à Graff (1987), não considera a escrita, em si mesma, responsável por transformações nas culturas. Para ele, a própria linguagem oral é capaz de gerar comportamentos tradicionalmente associados à escrita, como a fixação, a separação e a abstração. Além disso, as pinturas, os rituais e as narrativas, típicos das culturas de oralidade primária são capazes de transformar a evanescência do som em algo quase permanente, distanciando as pessoas do imediato e desenvolvendo o pensamento abstrato.

A perspectiva de Ong (1998), para Street (1995), traz grandes marcas do evolucionismo, na medida em que investiga as sociedades contemporâneas que ainda se conservam "primitivas" com o objetivo de nelas encontrar o que teria sido o passado da sociedade ocidental. Trabalhos antropológicos realizados na atualidade têm mostrado a riqueza e a diversidade de culturas não avançadas tecnologicamente, evidenciando as multivariadas direções que a "evolução" pode tomar.

Ong apresentaria também uma visão evolucionista quando afirma, por exemplo, que as culturas orais vão, pouco a pouco, cedendo espaço à pene- 
tração da escrita, pois "devemos morrer para continuar a viver" (I 988, p.24), quando divide a "evolução" das culturas humanas em etapas: oral, quirográfica (ou manuscrita), tipográfica e eletrônica (Ong, 1986, p.47). É, porém, verdade que, às vezes, o autor parece querer relativizar essa posição, quando afirma, por exemplo, que a interação da escrita com as estruturas e práticas sociais, no decorrer da história, não segue o mesmo desenvolvimento em todas as culturas (Ong, 1986).

Também o histórico traçado por Cook-Gumperz e Gumperz ( 981 ) caracteriza-se por certo evolucionismo, quando não considera as especificidades e diferenças entre países, regiões, classes ou grupos sociais. Ao terminar sua leitura, assim como de outros textos já referidos que investigam as relações entre oralidade e letramento, tem-se a impressão de que toda a "humanidade" passou igualmente pelo mesmo processo, constituído de etapas mais ou menos delimitadas, e caminha para um mesmo fim. Nesse sentido, o histórico elaborado pelos autores é interessante como uma referência geral, como um quadro que deve ser nuançado, relativizado, complexificado enfim.

Em muitos estudos, a visão evolucionista é acompanhada ou baseada numa supervalorização da escrita, ou mesmo se baseia nela, Havelock ( 1988), como se viu, afirma que a invenção do alfabeto grego constitui o marco fundador da História humana, noção criticada já há algumas décadas por tendências contemporâneas da historiografia - por muito tempo, denominou-se o período anterior à escrita de "pré-história". Ong (1998), por sua vez, ao mesmo tempo em que valoriza a linguagem oral, reconhecendo-a como natural e de primordial importância, considera a escrita como uma tecnologia capaz de alargar a potencialidade da linguagem e reestruturar o pensamento. No trecho que se segue, é possível perceber essas questões:

Na realidade, as culturas orais produzem realizações verbais impressionantes e belas, de alto valor artístico e humano, que já não são sequer possíveis quando a escrita se apodera da psique. Contudo, sem a escrita, a consciência humana não pode atingir o ápice de suas potencialidades, não é capaz de outras criações belas e impressionantes. A cultura escrita, como veremos, é imprescindível ao desenvolvimento não apenas da ciência, mas também da história, da filosofia, ao entendimento analítico da literatura e de qualquer arte e, na verdade, à explicação da própria linguagem (incluindo a falada). (Ong, 1998, p.23) 
Além de supervalorizar a escrita, muitos trabalhos consideram que o único sistema de escrita válido e que demonstra a capacidade de abstração humana é o alfabético, como já foi mencionado. Na percepção de Ong (1998), por exemplo, a escrita é definida como uma representação de sons e não de coisas. Desse modo, na avaliação de Street (1995), o autor exclui os vários sistemas de escrita baseados em pictogramas e ideogramas, em marcas semióticas de vários tipos e mesmo o alfabeto fenício que, apesar de semeIhante à "verdadeira" escrita, não tinha a representação dos sons das vogais.

Desse modo, em muitos trabalhos sobre oralidade e letramento, a "evolução" é considerada linearmente, como se todos os povos caminhassem, alguns de modo mais lento, outros de forma mais rápida, em direção a um único fim. Fundamentando essa concepção, encontra-se uma visão evolucionista e teleológica da história. Eliminam-se as descontinuidades e as contradições na elaboração de uma história linear, homogênea e coerente (Foucault, 1972). Esses pressupostos, que fundamentaram inúmeros trabalhos contemporâneos em diversas áreas do conhecimento, têm sido sistematicamente questionados quando, há pelo menos duas décadas, teóricos agrupados em torno do que se convencionou denominar pós-modernismo tornaram evidentes também as "misérias" da razão, as contradições da tecnologia, as descontinuidades na História, a diversidade e a especificidade de cada cultura etc.

No entanto, muitos trabalhos do próprio campo de estudos sobre oralidade e escrita têm também criticado e relativizado esses pressupostos. Eisenstein (1985), por exemplo, afirma que não se pode atribuir à imprensa tantas conseqüências como as que normalmente são apontadas: a própria imprensa é produção de uma época e as diversas transformações ocorridas no momento de sua invenção são decorrentes de uma série de fatores. Em seu livro, publicado em 1979. The printing press as an agent of change ${ }^{12}$, a autora busca examinar as conseqüências históricas da introdução da imprensa no século XV na Europa, focalizando seu papel nas transformações das maneiras prévias das pessoas verem o mundo. A autora aponta, por exemplo, o fundamental papel que exerceu a constituição de todo um circuito que permitiu a produção e a circulação dos livros: os editores, os livreiros etc. Além disso, Eisenstein também relativiza e busca tornar mais complexas algumas afirmações que comumente

12. A imprensa como um agente de mudança (Eisenstein, 1979, não traduzido para o português). 
são feitas em relação às conseqüências da imprensa. Segundo a autora, normalmente se afirma que a imprensa provocou um movimento da "cultura da imagem" em direção à "cultura da palavra". No entanto, para ela, o inverso também foi verdadeiro: na mesma época e pelo mesmo processo, houve um movimento da palavra para a imagem. A autora investiga como as mudanças trazidas pela imprensa afetaram os grupos já letrados, perspectiva que denomina "revolução ignorada". Nesse sentido, seu interesse não é compreender como se deram as transformações de uma cultura oral para uma cultura impressa, mas de um tipo de cultura escrita (manuscrita/letrada) para outro (impressa).

Para Eisenstein, a verdadeira revolução teria se dado no século XII, quando o livro saiu dos conventos, das abadias e tornou-se leigo. No século XV, teria havido o que chama "evolução", já que as transformações se deram principalmente no âmbito da produção do objeto. A autora destaca a imprensa e o impressor como os dois principais agentes de mudança e relaciona o aparecimento da imprensa a outros movimentos ocorridos no início da Idade Moderna, como o Renascimento, a Reforma e a Revolução Científica. Nesse sentido, procura mostrar que a imprensa não foi responsável pelo Renascimento; que a religião possibilitou a socialização do impresso ao mesmo tempo em que se utilizou da imprensa para realizar censuras, através da publicação do Index, e que a imprensa permitiu popularizar a ciência moderna. Para a autora, é imprescindível considerar o contexto institucional de qualquer inovação tecnológica, sob o risco de se super ou subdimensioná-la. Chartier (1994), do mesmo modo, afirma que o advento da imprensa não foi o único responsável pela socialização da leitura, como tantas vezes se afirmou. Para o autor, na verdade, mais do que a imprensa, a transformação que mais contribuiu para a reestruturação do pensamento foi a invenção do suporte livro, alguns séculos antes.

\section{CONSIDERAÇÕES FINAIS}

Como vimos no decorrer deste artigo, progressivamente alterou-se a abordagem dos estudos sobre a cultura da escrita. Mais do que descrever de maneira mais ou menos dicotomizada as diferenças entre a cultura escrita e a oral, passou-se a buscar apreender as condições sociais, históricas e técnicas em torno das quais, para diferentes casos históricos, construiu-se uma determinada cultura escrita e um conjunto determinado de impactos políticos, sociais e cultu- 
rais. Passou-se, portanto, a buscar compreender não a cultura escrita em sua oposição à cultura oral, mas culturas escritas. Para isso, formaram-se duas linhas principais de investigação. A primeira delas volta-se para o estudo, em grande escala, da entrada de sociedades no mundo da escrita, procurando responder como e em que condições a população dessas sociedades se alfabetizou, bem como o tipo de cultura escrita que se construiu nesse processo (ver, por exemplo, Graff, 1987; Furet, Ozouf, 1977). A segunda linha, por meio de monografias, volta-se para o estudo de práticas de leitura e escrita, de modos de inserção individuais em culturas escritas e da maneira pela qual essas culturas adquirem uma identidade específica, seja em razão das finalidades e dos usos que nela se fazem da escrita, seja em razão do modo pelo qual nela se relacionam o impresso e o manuscrito, assim como a oralidade. As investigações do segundo grupo, portanto, voltam-se, com ênfase, para a diluição das dicotomias dos primeiros estudos sobre a cultura da escrita, buscando compreender, por exemplo, como comunidades de intérpretes são criadas por meio da oralidade ou, ainda, como e por meio de que práticas uma scribal culture sobrevive, apesar de uma ampla difusão do impresso ${ }^{13}$.

No caso brasileiro, assim como no de outros países de escolarização e de difusão da imprensa tardias, ganha relevância, desse modo, a investigação sobre o papel desempenhado por práticas intelectuais ainda ancoradas na oralidade, no uso do manuscrito, na memorização e que utilizam outros vetores além da escrita, como as sociabilidades das feiras, das peregrinações ou o rádio. Nesse sentido, há certamente um amplo programa de pesquisas ainda por ser feito, buscando compreender melhor as especificidades da construção de culturas escritas nos diferentes espaços e tempos no país.

\section{REFERÊNCIAS BIBLIOGRÁFICAS}

AKINNASO, F. On the differences between spoken and written language. Language and speech, v.25, part 2, p.97-125, 1982.BATISTA, A. A. G. Papéis velhos, manuscritos impressos: paleógrafos ou livros de leitura manuscrita. In: ABREU, M.; SCHAPOCHNIK, N. (orgs.). Cultura letrada no Brasil. objetos e práticas. Campinas: Mercado de Letras, 2005. p.76-I 00.

13. Ver, para um resumo desses estudos, Chartier, 2002; a respeito das interações, no caso brasileiro, entre oral e escrito, scriba/e writing culture, ver, respectivamente, Galvão (2000) e Batista (2005). 
BURKE, P. Abertura: a nova história, seu passado e seu futuro. In: BURKE, P. (org.) A Escrita da história: novas perspectivas. São Paulo: Unesp, 1992. p.7-37.

CHAFE, W. Linguistic differences produced by differences between speaking and writing. In: OLSON, D. R.; TORRANCE, N.; HILDYARD, A. Literacy, language and learning. the nature and consequences of reading and writing. Cambridge: Cambridge University Press, 1985. p. $105-123$.

CHARTIER, R. Os Desafios da escrita. São Paulo: Editora da Unesp, 2002.

A Ordem dos livros. leitores, autores e bibliotecas na Europa entre os séculos XIV e XVIII. Brasília: Editora Universidade de Brasília, 1994.

COOK-GUMPERZ, J.; GUMPERZ, J. From oral to written culture: the transition to literacy. In: WHITEMAN, M. F. (ed.). Varition in writing. functional and linguistic-cultural differences. Hillsadale: Erlbaum, 1981. p.89-109.

EGAN, K. Literacy and the oral foundations of education. Havard Educational Review, v.57, n.4, p.445-472, nov. 1987.

EISEINSTEIN, E. On The printing press as an agent of change. In: OLSON, D. R.; TORRANCE, N.; HILDYARD, A. Literacy, language and learning: the nature and consequences of reading and writing. Cambridge: Cambridge University Press, 1985. p. 1 9-33.

The Printing press as an agent of change: communication and cultural transformation in early modern Europe. Cambridge: Cambridge University Press, 1979. 2v.

Paulo: Ática, 1998.

A Revolução da cultura impressa: os primórdios da Europa Moderna. São

FOUCAULT, M. A Arqueologia do saber. Petrópolis: Vozes, 1972.

FURET, F. ; OZOUF, J. Lire et écrire: l'alphabétisation des français de Calvin à Jules Ferry. Paris: Minuit, 1977.

GALVÃO, A. M. de O. Ler/ouvir cordéis em Pernambuco: 1930-1950. Belo Horizonte, 2000. Tese (dout.) Faculdade de Educação, UFMG.

GINZBURG, C. O Queijo e os vermes. o cotidiano e as idéias de um moleiro perseguido pela Inquisição. São Paulo: Companhia das Letras, 1987.

GOODY, J. The Domestication of the savage mind. Cambridge: Cambridge University Press, 1977.GOODY, J., WATT, I. The Consequences of literacy. Comparative Studies in Society and History, v. 5, n. 3., p.304-345, 1963.

GRAFF, $\mathrm{H}$. The Legacies of literacy. continuities and contradictions in western cultures and society. Bloomington: Indiana University Press, 1987. 
HAVELOCK, E. The Coming of literate communication to western culture. In: KINTGEN, E. R.; KROLL, B. M.; ROSE, M. Perspectives on literacy. Carbondale, Edwardsville: Southern Illinois University Press, 1988. p. I27-134.

. A Equação oralidade-cultura: uma fórmula para a mente moderna. In: OLSON,

D. R.; TORRANCE, N. (org.) Cultura escrita e oralidade. São Paulo: Ática, 1995. p. I7-34. . Preface to Plato. Cambridge: Havard University Press, 1963. Prefácio a Platão. Campinas: Papirus, 1997.

LÉVY-STRAUSS, C. O Pensamento selvagem. Rio de Janeiro: Zahar, 1983.

LORD, A. B. The Single of tales. Cambridge: Havard University Press, 1960.

MARTIN, H. J.; FEBVRE, L. O Aparecimento do livro. São Paulo: Hucitec, 1992.

MCLUHAN, H. M. A Galáxia de Gutenberg. São Paulo: Nacional; USP, 1972.

ONG, W. J. Oralidade e cultura escrita: a tecnologização da palavra. Campinas: Papirus, 1998. [original inglês: 1982]

Writing is a technology that restructures thought. In: BAUMANN, G. The Written word: literacy in transition. Oxford: Clarendon Press, 1986. p.23-50.

PARRY, M.. L'Épithète traditionell dans Homère: essay sur un problème de style homérique. Paris: Societé Editrice Les Belles Letres, 1928.

SMITH, L. W. An interactionist approach to the analysis of similarities and differences between spoken and written language. In: JOHN-STEINER, V.; PANOFSKY, C.P.; SMITH, L. W. (ed.) Sociocultural approaches to language and literacy. an interactionist perspective. Cambridge: Cambridge University Press, 1994. p.43-81.

STREET, B. V. Social literacies. critical approaches to literacy in development, ethnography and education. London, New York: Longman, 1995.

TANNEN, D. Relative focus on involvement in oral and written discourse. In: OLSON, D. R.; TORRANCE, N.; HILDYARD, A. Literacy, language and learning: the nature and consequences of reading and writing. Cambridge: Cambridge University Press, 1985. p. $124-147$.

ZUMTHOR, P. A Letra e a voz: a "literatura" medieval. São Paulo: Companhia das Letras, 1993.

Recebido em: abril 2005

Aprovado para publicação em: novembro 2005 